\title{
INTERACTIVE ONLINE PATH FOR ENGLISH REMEDIAL WORK AT SECONDARY SCHOOL
}

\author{
Elisa Corino $^{1}$, Cecilia Fissore ${ }^{1}$ and Marina Marchisio ${ }^{2}$ \\ ${ }^{I}$ Dipartimento di Lingue e Letterature Straniere e Culture Moderne \\ Via Giuseppe Verdi Fronte 41, 10124 Torino TO, Italia \\ ${ }^{2}$ Dipartimento di Biotecnologie Molecolari e Scienze per la Salute \\ Via Nizza 52 - 10126 Torino TO, Italia
}

\begin{abstract}
According to the annual report of the EF EPI (Education First - English Proficiency Index), the level of fluency in English by Italians is among the lowest in Europe. It is important that young people acquire language skills at school, especially during secondary schools, so as not to be penalized at university or when looking for work. However, English is one of the most difficult subjects for students and remedial work interventions are often necessary. In this, but also in general in teaching and learning English, technologies can offer important support. The University of Turin has designed and implemented innovative methodologies for remedial work, based on the use of an integrated Digital Learning Environment. The context of this research is an interactive online course for the remedial work of English which involved 11 classes of a secondary school for a total of 265 students. Our research questions concerning the design and implementation of activities and resources to involve students and what utility and interest they have induced in students. To answer the research questions, the paths on the platform and the activities and resources created by the tutors were analyzed. To understand if students and teachers appreciated the remedial work path and if they considered it useful, their answers to the final questionnaire, completed at the end of the remedial work path, were analyzed.
\end{abstract}

\section{KEYWORDS}

Adaptive Interactive Lessons, Digital Learning Environment, English Remedial Work, Feedback, Interactive Teaching Materials, Tests with Automatic Assessment

\section{INTRODUCTION}

According to the annual report of the EF EPI (Education First - English Proficiency Index) which detects the level of knowledge of the English language, the level of fluency in English by Italians is among the lowest in Europe (EF EPI, 2019). This situation clashes with the globalized nature of the world and may preclude opportunities for future employment. School has a primary role in assuring a proper language education and the development of skills, which will allow students to successfully enter foreign universities or the labour market. Although the Italian National guidelines for secondary education state B2 as the exit level to be reached at the end of upper secondary school, according to data from the EF EPI, only $30 \%$ students have it. In addition, the percentage of students who reach B2 level falls from $40 \%$ in urban schools to $25 \%$ in provincial schools. Despite its universally acknowledged importance and pervasiveness in our everyday life, it appears that English is one of the subjects where students have most difficulties and motivation. This might be partly due to the persistence of traditional teaching, mainly focused on theoretical grammar skills and structural knowledge over functional competence and communication, which is still widely practiced despite the guidelines coming from research and good teaching practices. To face the difficulties in English, teachers and institutes, but also students and parents, devote many resources in terms of time and actions taken. As the research of the last two decades highlights, modern technologies and among them CALL (Computer Assisted Language Learning) and MALL (Mobile Assisted Language Learning) can offer valuable support for learning and teaching languages. They can be used by teachers to enrich lessons in the classroom, all the more to involve the least motivated or most struggling students (Wu, 2003; Alizadeh, 2016). The literature about the use of ICT in the language classroom is substantial and there are lots of projects focusing on good practices to integrate the active use of technology with the last waves of theoretical research about language teaching and 
learning - "ITIL2- Interactive Teaching in Languages with Technology" (http://www.itilt2.eu), "CATAPULT-Computer Assisted Training and Platforms to Upskill LSP Teachers" (http://catapult-project.eu) and "PETALL-Pan European Tasks for Language Learning" (http://petallproject.eu/petall/index.php/en/) among others - but little has been done about the specific needs of remedial work. In the light of that, the University of Turin has designed, studied and developed innovative methodologies to help remedial work and reduce school failures. These methodologies are characterized by the use of a Digital Learning Environment (DLE), a virtual space shared by students and teachers, both for face-to-face activities and for remote online activities. The DLE, implemented on a Moodle platform integrated with an automatic assessment system (AAS) and a web conference service, is based on constructivist theory, student-centered learning and collaborative learning. The context of this research is an interactive online course for remedial English classes which involved 11 classes of a secondary school for a total of 265 students. The school is the Amaldi Sraffa Higher Education Institute of Orbassano (in the province of Turin) and students from grade 9 to grade 11 were involved. The course should have included afternoon remedial activities in the classroom and remote online activities, both conducted by university tutors of the Master's Degree in Modern Languages and Literatures specially trained. However, due to the Covid-19 emergency and the consequent closing of the schools, the experience took place entirely online and the tutors only met their students through the platform. The course was organized within the integrated DLE and lasted about 3 months (from March 2020 until the end of the school year in May 2020). During this period, the tutors held weekly synchronous online meetings and they designed and created remedial activities and resources, always available to students on the platform. Our research questions are: "How were the activities and resources designed and implemented to involve students, given the emergency and the exclusively online nature of the experience?" and "What usefulness and satisfaction did the activities and resources have for the students and teachers, within the path of online remedial work?". To answer these questions, the interactive paths and the activities and resources created by tutors were analyzed in detail. The methodologies used by the tutors for the implementation, with the support of the trainers, of the platform activities were also analyzed. Students' and teachers' responses to the final questionnaire completed at the end of the remedial work process were also analyzed.

\section{TECHNOLOGIES FOR ENGLISH TEACHING AND LEARNING: AN INTERACTIVE COLLABORATIVE LEARNING ENVIRONMENT}

The development, the implementation and the assessment of language learning and teaching activities have significantly increased with the use of online technologies and mobile devices (Milthorpe et al., 2018). ICT and language education have been a fundamental combination and a precious resource for foreign language teachers since the 60 s of the last century, when technologies started to be seen as a necessary support to language learning (Cuccurullo, 2012). Over the years, there have been different approaches to the use of technologies - often influenced by the theories of language acquisition - and numerous technological tools have been used in the teaching/learning processes of foreign languages. In recent years, CALL and MALL have contributed to forge paths to language learning in ways that do not replace the work of teachers in the classroom but complement it in significant manners.. The importance of ICT as components of the teaching-learning environment is generally acknowledged by literature (among the manifold works on the integration of technology and the language classroom, Chapelle \& Sauro 2017 and Stanley 2013) in relation to all the benefits that this combination can have on the students' abilities, cognitive styles, learners' autonomy and motivation. Yet, online, blended, e-learning, or technology-enhanced learning remains an area of significant challenge for humanities that traditionally prize face-to-face pedagogical methodologies such as the lecture, and small group discussion and debate (Blended). A DLE, i.e. an online virtual space shared by teachers and students, can allow teachers to enhance the teaching and learning of foreign languages. Currently, various platforms are available (for example Padlet, Edmodo, Gsuite, Moodle), some free and some not, some simpler and more basic and some more complex with plug-ins and possible integrations with other software. What we mean by DLE integrated into teaching is much more than a platform. In a DLE it is important both the technological component and the human component, and how the activities are designed for the interactions between students, teachers and peers. Through a DLE one can propose many different types of activities in a single shared environment; it is important in an online teaching context, but it can also integrate the teaching experience into ordinary teaching in classroom-based or in a blended mode. And what is more, the availability 
of a platform on mobile devices can render even greater benefits for both language teachers and learners (Herrera Mosquera, 2017). A DLE foster the establishment and expansion of a community by offering a "real" context for interaction and support virtual communities, with no physical walls defining the borders of the place where the community resides and works (Ligorio and Van Veen, 2006). From the didactic and pedagogical point of view, DLEs should be designed to support and foster constructivist learning, thus enabling students to actively build their knowledge with the mediation of experiences and relationships with the environment and community (von Glasersfeld, 1989), stimulating motivation and autonomous investigation and, and redefining the role of teachers as facilitators rather than sources of knowledge. A central factor in the learning environment is feedback: frequent and well-structured feedback helps learners understand where they are, where they are going and what they should do in order to reach their goal, giving information not only about how the task was performed, but also about the process to be mastered, and enabling self-regulation and self-monitoring of actions (Hattie and Timperley, 2007). Digital technologies can support and expand feedback practices and, returning individualized information to students and teachers in real time, they can support and enhance learning processes. Among the requirements of an effective DLE that fulfils the constructivist and experiential ideal, there should be: the possibility for students to create and publish their own works, immediately usable and shared within the community, to compare it, and to actively collaborate with the teacher or other students; the implementation of activities that promote active exploration for students and that react to the user's action giving a feedback. Activities in which digital tools are used demonstrate ways that technology can be deployed to engage students, to look at texts in fresh ways, and to make learning more interactive and student driven (Milthorpe et al., 2018).

\section{THE ONLINE PATH FOR ENGLISH REMEDIAL WORK}

The University of Turin (Unito) has designed, studied and developed innovative methodologies for the reduction of school failures and has applied them in different contexts (Cavagnero et al., 2015; Fissore et al., 2019, In press). The Unito DLE is a Moodle platform (managed by the ICT services of the Department of Computer Science of the University of Turin), integrated with the AAS Moebius Assessment for the creation of online formative tests. This AAS allows the creation of adaptive questions that provide students another chance when they give an incorrect response and that can be adapted to: provide more information; let the student try a simpler version of the question; lead the student through the exercise one step at a time; and present whatever other approach the instructor feels is appropriate. This type of questions with interactive and immediate feedback is very suitable for automatic formative assessment (Barana et al., 2019; Marello et al., 2019). The platform (available at the link https://scuolapertutti.i-learn.unito.it/) is also integrated with a web conference system for online tutoring andfor all contents the EasyReading font with high readability is used. Using Moodle in teaching and learning is not innovative. The novelty of our work consists in the use of a DLE integrated with an AAS, to carry out activities that involve students, tutors and teachers (online or in the classroom when it is again possible) in a little explored and studied context such as that of recovery. For this reason, a qualitative and not quantitative analysis is proposed, which concerns the methodologies adopted for the recovery and not the numbers of how much the students have improved. The DLE allows to propose a remedial work intervention different from the traditional one, which in addition to the development of knowledge and skills related to learning English, is also concentrated on enhancing interest in the matter and trust in the possibility of success. The remedial work path of English took place within the third edition of the "Scuola per Tutti" (which in English means "School for Everyone") project. The project took place in the secondary school Amaldi-Sraffa of Orbassano in the province of Turin in order to recover school failures of 9th, 10th and 11th grade students in English, Mathematics, Latin and Physics (Barana et al., 2020). The goals of the project were to overcome learning difficulties, to reduce the phenomenon of early school leaving, to increase motivation in studying and to facilitate the transition between lower and upper secondary school. In this research we will focus exclusively on the third edition of the remedial work path for English, as the first two editions have been used to design and test methodologies for teaching English. The remedial work path lasted about three months in the second part of the 19/20 school year.. At the beginning of the project, the teachers selected the students with deficiencies in English (insufficiency between 4 and a half and 5 and a half). Throughout the period, students were followed by university tutors, specially trained on the project methodologies and on the use of the technologies involved. Initially the remedial work path included activities 
within the DLE of three types: synchronous face-to-face activities, synchronous online activities via web conference and online asynchronous activities. Due to the emergency from Covid-19 and therefore the closure of the schools, the remedial work activities took place exclusively online remotely via the DLE. This led to a redesign and reformulation of the remedial work path. On the one hand, synchronous online meetings have been enhanced to give tutors and students the opportunity to get to know each other and relate as much as possible to each other. On the other, asynchronous platform activities have been enhanced to give students the opportunity to carry them out when they could and when they wanted (compatibly with daily online lessons). A further consequence was that of deciding to involve all the students in the class, in addition to the students selected by the teachers, to offer everyone support during the emergency. The teachers were involved throughout the course and played a key role: they indicated to the tutor the topics to be addressed with the students, reminded the students to connect to the online meetings and carry out the activities and supported the tutor in creating the material. Conversely, the tutors constantly updated the teachers on the activities carried out with the students, on the results achieved and on the involvement of the students. Finally, the tutors received constant support from the researchers: in implementing the project methodologies, in the use of technologies, in making the materials more interactive and training and in relating with the students. The remedial work path involved 11 classes of 4 teachers for a total of 265 students. The classes were grouped into 5 groups and 5 interactive online courses were set up, to which students, their teacher and tutor always had access. Each path was managed by one of the three tutors (two tutors followed two paths). The use of the platform makes it possible to track all student activities within the course. The remedial work path was organized in this way: during the online meetings the tutor reviewed the disciplinary topics indicated by the teacher, after which they created and made available material that students could explore and do during the week before the next meeting. Students could also use the course forum at any time to ask questions to the tutor of a theoretical nature, on the materials made available or on the use of the platform.

\section{RESULTS}

Our research questions concern the design and implementation of activities and resources to involve students and what utility and interest they have induced in students. To answer the research questions, the five remedial work paths on the platform and the activities and resources created by the tutors were analyzed in detail. The activities and resources were analyzed according to their characteristics and the type of interactivity they offer. All the activities and resources created by the tutors have been classified according to the following categories: tests with automatic assessment, interactive lessons, interactive resources, submissions of tasks, recordings/podcasts and static resources (pdf files, URLs, images). The methodologies adopted by tutors were analyzed to make digital materials as interactive as possible, to involve students more and give them immediate and interactive feedback. Some representative examples will be shown. To understand if the students and teachers appreciated the remedial work path and if they considered it useful to recover their gaps, their answers to the final questionnaire, completed at the end of the remedial work path, were analyzed. In particular, the following questions were analyzed: the relationship of the students with the English subject before and after the course; their main difficulties; reflections on their progress; reflections on interactions with tutors and on the support they have given; reflections on the platform used for the course and on the activities and resources created by the tutors. The questionnaire was optional for the students and, having to fill it in at the end of the school year, not everyone replied. In total 101 students replied.

\subsection{Analysis of the Activities and Resources}

A total of 217 activities and resources for students on multiple topics were created in the various courses. Figure 1 shows a summary of the classification of the activities and resources in the various categories. At the beginning of the course, tutors shared many static resources such as theoretical pdf files, concept maps, power point presentations, images or URLs for further information. This can be explained in several ways: at the beginning of the course, the tutors were not skilled enough to exploit the potential of the DLE and chose to use tools that they were already familiar with; it is very easy to find very valid and interesting open static resources on the net; in some cases the tutors used references to textbooks that all students had. 


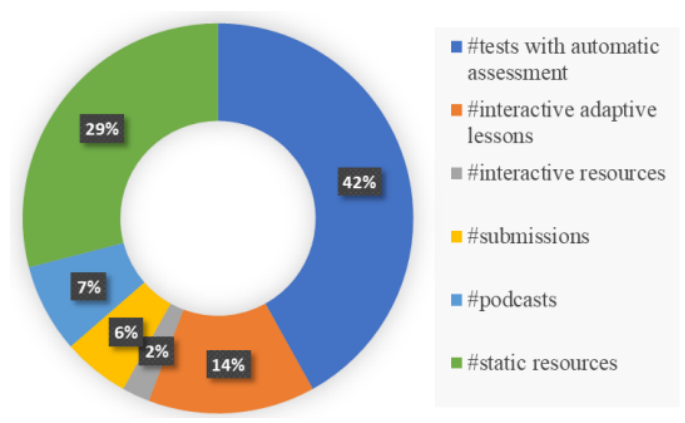

Figure 1. Summary of the classification of the various activities and resources in the remedial work paths

These contents can be very useful, such as videos or podcasts to practice listening or pages and conceptual maps for review, however making them available to students may not be enough. The researchers then suggested to tutors to create adaptive interactive lessons: a collection of customizable html pages. Each page can have content (video, audio, image, text, concept map, etc.) or questions. Student can navigate between the various pages and view different contents according to the choice (answer given, go to the next page, go to the previous page, select a specific page, etc.). Different comments/answers can be presented depending on the choice and students can be directed to navigation. For example, a lesson on the infinitive of purpose was proposed. In the first part of the lesson, students were asked to watch and listen to a video of a very famous English song ("The Scientist" by Coldplay) with English subtitles, in which the construct was often used. In the second part of the lesson a summary explanation was proposed through a concept map and a narrative explanation. After this explanation, students could choose whether to watch the video again or try to take a short quiz. In the quiz different sentences were presented and the students had to understand if the "to" in the sentence represented an infinity of purpose. For example, in the sentence "I went to the cinema to watch The Avengers!" students could choose from the answers: only the first, only the second, or both. Students had personalized feedback depending on the response, for example if they selected "only the first" they had the feedback "Pay attention! The first "to" is a prepositions of movement", if they selected "both" they had the feedback "Try to reason, where is the purpose in this sentence?". Students who answered all questions correctly concluded the lesson, while students who made mistakes were presented with an additional page of explanation. The lesson could also be repeated several times. This type of adaptive presentation of content and questions makes students the protagonists of their learning, forces them to think about what is required and stimulates them to be active in building their knowledge. Often, at the end of an interactive theory review lesson, students were offered tests with automatic assessment and immediate feedback. These tests, as shown in Figure 1, represent $42 \%$ of the activities carried out. For the creation of the tests, the tutors took inspiration from exercises in the textbooks, from open material on the web or from exercises provided by teachers. Initially tutors tended to reproduce the exercises by transcribing them with some modifications within the AAS. In the example question in Figure 2, students had to think about using "some" and "any" and complete sentences correctly.

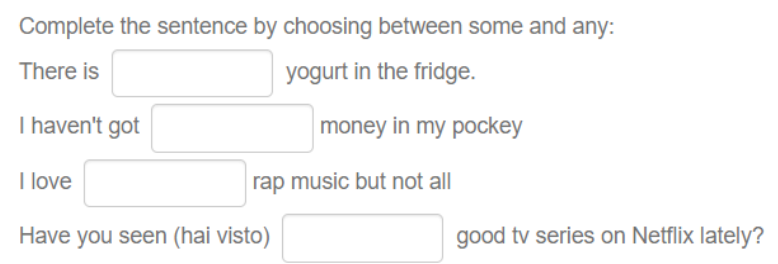

Figure 2. Example of initial question created by tutors with the AAS

In this case, the students had the assessment after having submitted the whole test, they did not have immediate and the simple "wrong answer" feedback does not give students information about their mistake and how to overcome it. It is possible to add final feedback, but students hardly look at it after submitting the test and seeing the score. Furthermore, they are probably no longer focused on this request because they answered the other questions as well. Trainers guided the tutors to create adaptive questions, more effective for formative assessment.. For example, the question seen above can be transformed into a question for 
formative assessment with immediate feedback. As in figure 3, the four cases can be proposed sequentially. After completing the first request, students can click on the "verify" button (which means "check" in Italian) and check the accuracy of the answer given, obtaining immediate feedback. In this way, if students make a mistake at the first request, they can rethink the reasoning and try to correct themselves, having experienced the previous result. After that, it is possible to insert feedback on the review of the theory directly within the question. In this way, students can actively review the rule, thinking about the answers entered and having more attempts available. By having immediate feedback, they can better acquire the general rule and put it into practice immediately. Finally, other requests are presented in the last part of the question to see if the student has internalized the rule correctly. The possibility of having more attempts available through a guided and interactive path is very important for the self-confidence of the students and can help to overcome the errors due to the correct insertion of the written answer. This type of activity allows students to practice independently when they prefer and to have immediate feedback on the activity carried out. Students can retry the test as many times as they wish and ask questions to the tutor or classmates in the forum if necessary. The tutor can view the students' answers and all attempts to answer, to be aware of the most frequent errors and any difficulties encountered. During synchronous online meetings, students can compare each other on the activity carried out and the tutor can give general feedback. In both activities, lessons and tests, adaptive teaching is proposed to activate effective formative assessment strategies, to give different feedbacks according to the level and responses of the students and to activate self-regulated learning.

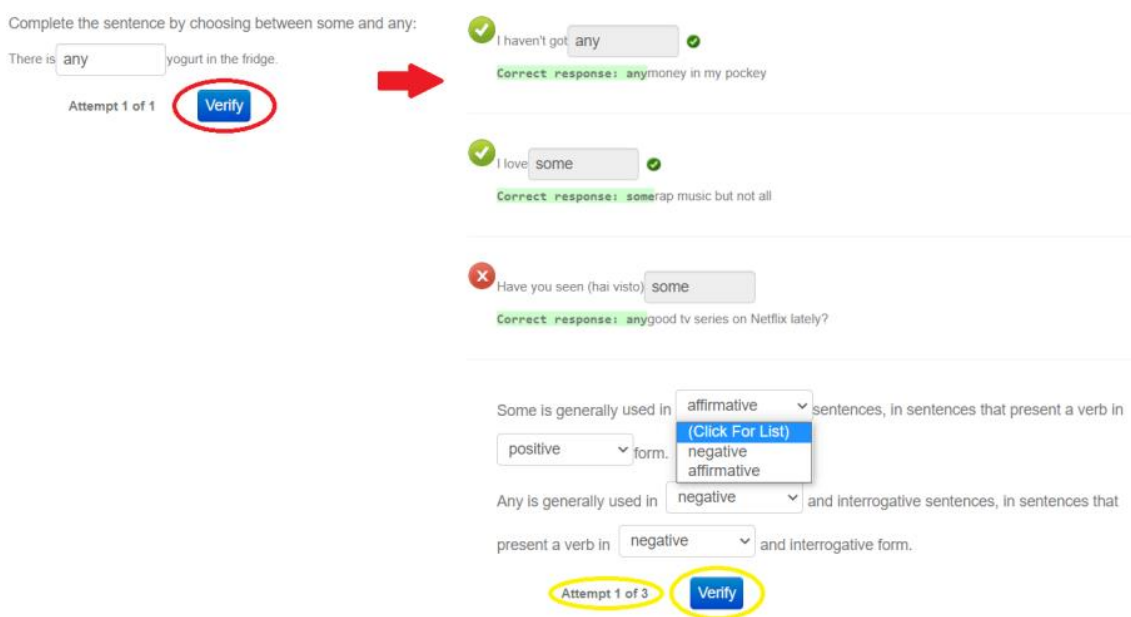

Figure 3. Previous example transformed for a more formative assessment

For other types of activities, such as writing a text or pronunciation exercises, tutors used the submission activity: the students submitted an online task and tutors returned feedback after a few days. In online education it is important to give continuous feedback to students but at the same time it can be important to receive it from students. For example, after a phonetic activity, a tutor submitted short surveys to students in order to get feedback on the usefulness and appreciation of the activities carried out. A student wrote that she really enjoyed the activity and that the most stimulating aspect was: "Knowing that there is no need to pronounce words like a native Englishman would do". This confirms that speaking in English is one of the activities in which students have the most difficulties. The latest types of activities shared by the tutors are SCORM (Shareable Content Object Reference Model) activities, a collection of specifications that enable interoperability, accessibility and reusability of web-based learning content. All activities and resources within the DLE were accessible to students at any time, via computer or mobile device. All students could choose when to dedicate themselves to the review activities. The activity with students gave the tutors the opportunity to receive very useful feedback and to reflect on the prepared activities. 


\subsection{Students' and Teachers' Satisfaction with the Remedial Work Path}

In the final questionnaire, students had to give themselves a score from " $1=$ insufficient" to " $5=$ excellent" in different aspects of English included in the Table1. The results are good because in all aspects the scores have improved (except for the participation in the class lesson, but this could be difficult to assess given the emergency). The teachers also confirm these results. They were asked to give a score to each student, with the previous scale, before and after the course. All aspects have improved. In particular, the average score increased from 2.84 to 3.35 in the knowledge of the subject, from 2.85 to 3.36 in the study at home and from 2.88 to 3.38 in the confidence in the possibility of being able to recover. $90 \%$ of teachers thought the course was useful. The most significant reasons given by the teachers regarding the success of the course were: "the course proposed the discipline in a different and alternative way"; "the student has improved a lot thanks to the course"; "The course allowed the student to consolidate elementary contents that could no longer be reviewed in the class"; and "The course changed the student's attitude to study". As regards the reasons for the failure of the course, the reasons were: "the student generally showed little interest in the subject, despite having acquired knowledge thanks to the course" and "In the latter part of the school year, too many commitments and too many hours spent in front of the screen prevented a profitable". Students appreciated the course modalities in the following aspects (which they rated with the same scale as before): the number of meetings (3.78), the explanations of the tutor (3.65), relationship with the tutor (3.88), online dating as a support during an emergency (3.30). The students also appreciated the fact that they have interactive materials always available on the platform with an average value of 3.57 and the interactivity of these materials with an average value of 3.41. To the question "Do you think that interactive theory and review materials can be more useful and interesting than static ones?" $81 \%$ of students answered yes. The most significant responses to the request to explain why were: "interactive materials stimulate interest in the material treated"; "students are more involved"; "I find it useful to receive the correction immediately"; "with interactive materials you apply your knowledge and understand better"; "they can be more fun"; "because they stimulate you to be always concentrated and at a distance it is a necessary thing because at home we are constantly distracted". Most of the students who answered no reported that "taking lessons in class is irreplaceable" or that they prefer classical study to technology. Regarding the tests with automatic assessment, the students appreciated the following aspects indicating a score from " $1=$ not at all" to " $5=$ very much": perform the tests on the computer (3.53); always have access to tests with the possibility to try them several times (3.60); have immediate feedback (3.80); have multiple attempts to respond (3.41); have questions of different types available (3.43). The students were asked "If you had difficulties in the course subject, did you manage to recover them?", with the same scale as before. The answer is very positive because the average value of the answers was 4.47 with a standard deviation of 1.47 .

Table 1. Comparison of students' answers on various aspects of English between before and after the remedial work path

\begin{tabular}{lllll}
\hline & \multicolumn{3}{l}{ Mean before } & Dev.St. before \\
\hline Interest in the subject & 3.59 & 0.85 & 3.72 & 0.92 \\
Knowledge of the subject & 3.27 & 0.85 & 3.57 & 0.83 \\
Participation in the class lesson & 3.73 & 0.87 & 3.64 & 0.94 \\
Study at home & 3.22 & 0.92 & 3.35 & 0.88 \\
Confidence in the possibility of being able to recover & 3.54 & 1.04 & 3.78 & 0.92 \\
\hline
\end{tabular}

\section{CONCLUSIONS}

In this paper an interactive path for the remedial work of English has been presented. The course was carried out online through an integrated DLE, which allows to propose student-centered learning in which students are active and responsible participants in their own learning. Students can choose between the different types of activities and resources proposed by the tutors and carry them out independently when they prefer, get feedback on the work done and actively collaborate with the tutor or with the other students. The tutors, with the support of the researchers, were able to design and create interactive activities and resources, especially tests with automatic assessment with immediate and interactive feedback. The university tutors had the opportunity to have a first experience of teaching support with secondary school students, which is also useful to understand 
if this can represent their future work. Furthermore, during the experience, they were able to train and put into practice the innovative teaching methodologies proposed. At the end of the experience the tutors have gained skills and we think that this type of training could also be very useful for pre-service teachers. Students appreciated the remedial work path and the interactive character of the course. Most of the students overcame their initial difficulties with the subject. In the coming months, students' participation in online meetings and their responses in different types of activities will be analyzed in detail. The opinion of the teachers was also positive. Most of the teachers felt that the course was useful and that, despite the difficulties due to the emergency period, most of the students took advantage of the experience. This remedial work path could be extended to more students and could last the whole school year in the order of giving greater and constant support. The teaching materials created by tutors could be used by the teacher for normal lessons, with some additions or modifications. In this regard, it could be interesting to enhance the training of teachers on the use of the methodologies and technologies proposed in order to use them in their daily teaching. Finally, taking inspiration from this experience, an online remedial work path for English could be designed and implemented to help students in the transition from lower to upper secondary school.

\section{REFERENCES}

Alizadeh, M, 2016. The impact of Motivation in English Language Learning, in International Journal of Research in English Education, Vol. 1, No. 1, pp. 11-15.

Barana, A. et al., 2019. Adapting STEM Automated Assessment System to Enhance Language Skills, in: Proceedings of the 15th International Conference ELearning and Software for Education. Bucharest, pp. 403-410.

Barana, A. et al., 2020. An online math path to foster the transition of students between lower and upper secondary school, in: Proceedings of the 16th International Scientific Conference ELearning and Software for Education. Carol I National Defence University Publishing House, Bucharest, pp. 568-575.

Cavagnero, S.M., Gallina, M.A., Marchisio, M., 2015. School of tasks. Digital didactics for the recovery of scholastic failure. Mondo Digitale, Vol. 14, pp. 834-843.

Chapelle, C., Sauro, S., 2017. Introduction to the the Handbook of Technology and Second Language Teaching and Learning, Wiley, pp. 1-9.

Cuccurullo, D., 2012. La didattica delle lingue straniere con le ICT. ANSAS 2012, pp. 1-83.

EF EPI, 2019. Indice di Conoscenza dell'Inglese EF, 100 Paesi e regioni classificati in base alla padronanza dell'inglese.

Fissore, C. et al., 2019. University tutoring actions using an integrated online platform, in: 6th International Conference on Cognition and Exploratory Learning in the Digital Age (CELDA 2019). IADIS Press, pp. 69-76.

Fissore, C., Marchisio, M., Rabellino, S., In press. Online tutoring through an integrated platform to support learning Mathematics at lower secondary school. Proceedings of the 14th International Conference on e-Learning.

Graham, S., 2013. Language learning with Technology, Cambridge University Press.

Hattie, J., Timperley, H., 2007. The Power of Feedback. Review of Educational Research, Vol. 77, No. 1, pp. 81-112.

Herrera Mosquera, L., 2017. Impact of Implementing a Virtual Learning Environment (VLE) in the EFL Classroom. Íkala Revista de Lenguaje y Cultura, Vol. 22, No. 3, pp. 479-498.

Ligorio, M.B., Van Veen, K., 2006. Constructing a Successful Cross-National Virtual Learning Environment in Primary and Secondary Education. AACE Journal, Vol. 14, No. 2, pp 103-128.

Marello, C. et al., 2019. Automatic assessment to enhance online dictionaries consultation skills, in: 6th International Conference on Cognition and Exploratory Learning in the Digital Age (CELDA 2019), IADIS Press, pp. 331-338.

Milthorpe, N. et al., 2018. Blended English: Technology-enhanced teaching and learning in English literary studies. Arts and Humanities in Higher Education, Vol. 17, No. 3, pp. 345-365.

Stanley, G., 2013. Language learning with technology: Ideas for integrating technology in the classroom. Cambridge University Press.

Von Glasersfeld, E., 1989. Constructivism in Education, in: Husen, T., Postlethwaite, T.N. (Eds.), The International Encyclopedia of Education. Pergamon Press, Oxford/New York, pp. 162-163.

Wu, X., 2003. Intrinsecò Motivation and Young Language Learners: The Impact of the Classroom Environment, in System, Vol. 31, No. 4, pp. 501-517. 